\title{
Guidelines for Selecting Codes for Ground-Water Transport Modeling of Low-Level Waste Burial Sites
}

Executive Summary

C. S. Simmons

C. R. Cole

May 1985

Prepared for the U.S. Department of Energy under Contract DE-AC06-76RLO 1830

Pacific Northwest Laboratory Operated for the U.S. Department of Energy by Battelle Memorial Institute 


\title{
DISCLAIMER
}

This report was prepared as an account of work sponsored by an agency of the United States Government. Neither the United States Government nor any agency thereof, nor any of their employees, makes any warranty, express or implied, or assumes any legal liability or responsibility for the accuracy, completeness, or usefulness of any information, apparatus, product, or process disclosed, or represents that its use would not infringe privately owned rights. Reference herein to any specific commercial product, process, or service by trade name, trademark, manufacturer, or otherwise, does not necessarily constitute or imply its endorsement, recommendation, or favoring by the United States Government or any agency thereof. The views and opinions of authors expressed herein do not necessarily state or reflect those of the United States Government or any agency thereof.

\author{
PACIFIC NORTHWEST LABORATORY \\ operated by \\ BATTELLE \\ for the \\ UNITED STATES DEPARTMENT OF ENERGY \\ under Contract DE-AC06-76RLO 1830
}

\begin{tabular}{|c|c|}
\hline \multirow{2}{*}{\multicolumn{2}{|c|}{ Printed in the United States of America }} \\
\hline & \\
\hline \multirow{2}{*}{\multicolumn{2}{|c|}{$\begin{array}{l}\text { National Technical Information Service } \\
\text { United States Department of Commerce }\end{array}$}} \\
\hline & \\
\hline \multirow{2}{*}{\multicolumn{2}{|c|}{$\begin{array}{c}5285 \text { Port Royal Road } \\
\text { Springfield, Virginia } 22161\end{array}$}} \\
\hline & \\
\hline \multirow{2}{*}{\multicolumn{2}{|c|}{$\begin{array}{l}\text { NTIS Price Codes } \\
\text { Microfiche A01 }\end{array}$}} \\
\hline & \\
\hline \multicolumn{2}{|c|}{ Printed Copy } \\
\hline & Price \\
\hline Pages & Codes \\
\hline $001-025$ & $\mathrm{~A} 02$ \\
\hline $026-050$ & $\mathrm{~A} 03$ \\
\hline $051-075$ & A04 \\
\hline $076-100$ & A05 \\
\hline $101-125$ & A06 \\
\hline $126-150$ & $\mathrm{~A} 07$ \\
\hline $151-175$ & A08 \\
\hline $176-200$ & A09 \\
\hline $201-225$ & A010 \\
\hline $226-250$ & A011 \\
\hline $251-275$ & $\mathrm{~A} 012$ \\
\hline $276-300$ & A013 \\
\hline
\end{tabular}


GUIDELINES FOR SELECTING CODES FOR GROUND-WATER TRANSPORT MODELING OF LOW-LEVEL WASTE BURIAL SITES

Executive Summary

C. S. Simmons

C. R. Cole

May 1985

Prepared for

the U.S. Department of Energy

National Low-Level Waste Management Program under Contract DE-AC06-76RLO 1830

Pacific Northwest Laboratory

Richland, Washington 99352 
. 


\section{PREFACE}

This document was written for the National Low-Level Waste Management Program to provide guidance for managers and site operators who need to select ground-water transport codes for assessing shallow-land burial site performance. The guidance given in this report also serves the needs of applications-oriented users who work under the direction of a manager or site operator.

This executive summary, published separately, gives managers and site operators an overview of the main guideline report. The guidelines are published in two volumes designed to support the needs of users having different technical backgrounds. Volume 1, titled "Guideline Approach," consists of Chapters 1 through 5 and a glossary. The introductory chapter, which is essentially a repetition of this summary, includes specific recommendations for decision-making managers and site operators on how to use these guidelines. Chapters 2 through 5 provide the more detailed discussions about the code selection approach. Volume 2, "Special Test Cases," is a set of appendices on the technical evaluation test cases designed to help verify the accuracy of ground-water transport codes. 


\section{ACK NOWLEDGMENTS}

We wish to thank many of our colleagues for their helpful comments and reviews of these guidelines. R. L. Skaggs, D. A. Myers, and G. Whelan not only provided invaluable reviews but also applied the guideline approach and concepts to modeling projects for other sponsors. P. J. Mitchell reviewed the executive summary and contributed further financial support from another Department of Energy program having related research objectives. We also thank C. T. Kincaid and G. W. Gee for their special assistance and review suggestions. We appreciate the outside critical review contributed by R. B. Stout and C. B. Ozaki of Lawrence Livermore National Laboratory. P. C. Hays and staff contributed a considerable effort to editing and revising the guidelines. 


\section{CONTENTS}

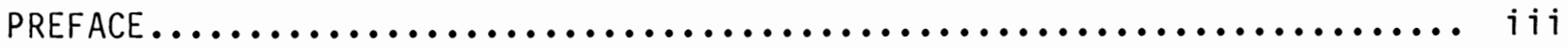

ACKNOWLEDGMENTS.................................... v

BACKGROUND.......................................... 1

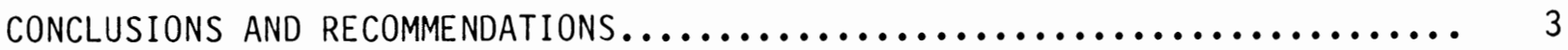

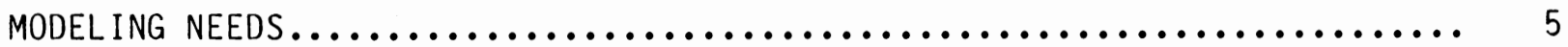

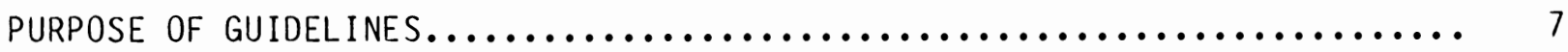

THE CODE SELECTION APPROACH............................. 8

STEP 1. DEFINE Site STUdY OBJECTIVES.................... 9

STEP 2. COLLECT AND ANALYZE SITE CHARACTERIZING DATA........... 10

STEP 3. FORMULATE THE CONCEPTUAL MODEL................... 12

STEP 4. IDENTIFY PROCESS DESCRIPTIVE EQUATIONS $\ldots \ldots \ldots \ldots \ldots \ldots \ldots \ldots$

STEP 5. SELECT THE COMPUTER CODES $\ldots \ldots \ldots \ldots \ldots \ldots \ldots \ldots \ldots \ldots \ldots \ldots \ldots \ldots \ldots \ldots \ldots$

STEP 6. COUPLE/INTERFACE THE SELECTED CODES $\ldots \ldots \ldots \ldots \ldots \ldots \ldots \ldots \ldots$

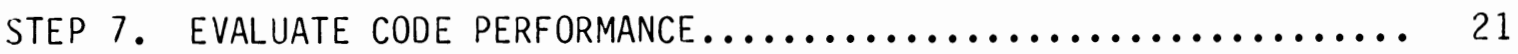

STEP 8. RUN SITE-SPECIFIC SIMULATIONS $\ldots \ldots \ldots \ldots \ldots \ldots \ldots \ldots \ldots \ldots \ldots$

STEP 9. COMPARE RESULTS WITH STUDY OBJECTIVES.............. 23

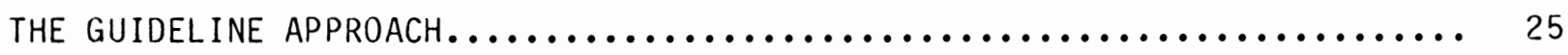

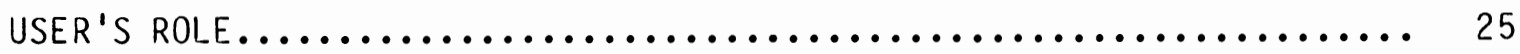

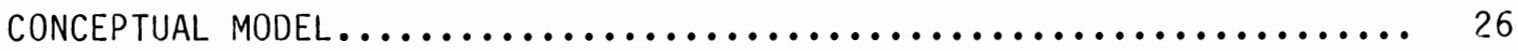

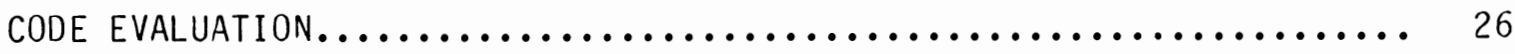

CODE SELECTION................................... 27

GUIDANCE FOR MANAGERS AND SITE OPERATORS .................... 28

STEPS FOR MANAGERS/SITE OPERATORS....................... 29 
Step 1. Identify Questions and Study Objectives............ 29

Step 2. Establish Costs and Schedules................... 29

Step 3. Enlist Aid of Professional Modelers............... 30

Step 4. Decide on Approach and Guide Code Selection.......... 32

Step 5. Facilitate Availability of Site-Specific Data........ 33

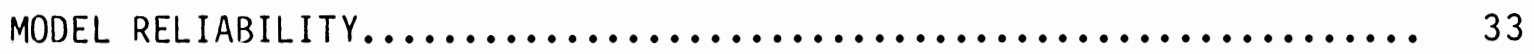

A RECOMMENDATION FOR RELIABILITY...................... 34

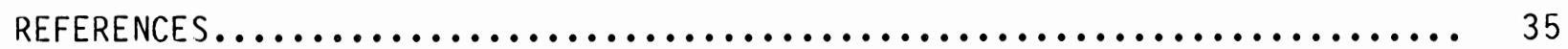




\section{FIGURES}

1. Systems Model Components............................... 9

2. Summary of the Hydro-Geochemical Processes Controlling Radionuclide Transport at a Shallow-Land Burial Site.............. 12

3. Summary of Process Models and Their Parameter Requirements, Used to Predict Unsaturated Zone Transport at a Shallow-Land

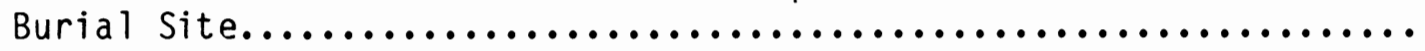

4. A Near-Field Conceptual Model: Hydrology of the ShallowLand Burial Trench...................................... 14

5. Hanford Site Unconfined Aquifer Boundary Showing the 200-West and 200-East Waste Burial Sites...................... 15

6. A Coupling Plan: Environmental Transport Pathways.............. 18 
BACKGROUND

This document was written by Pacific Northwest Laboratory under the sponsorship of the National Low-Level Waste Management Program to provide guidance to managers and site operators on how ground-water transport codes should be selected for assessing burial site performance. There is a need for a formal approach to selecting appropriate codes from the multitude of potentially useful ground-water transport codes that are currently available. Code selection is a problem that requires more than merely considering mathematical equation-solving methods. These guidelines are very general and flexible and are also meant for developing systems simulation models to be used to assess the environmental safety of low-level waste burial facilities. Code selection is only a single aspect of the overall objective of developing a systems simulation model for a burial site. The guidance given here is mainly directed toward applications-oriented users, but managers and site operators need to be familiar with this information to direct the development of scientifically credible and defensible transport assessment nodels.

The selection of appropriate computer codes should be based on first developing a relevant conceptual model for the specific burial site and associated ground-water system. A conceptual model is essentially a picture of a waste burial systen developed from the available site characterization data. The complexity of such a picture should be consistent with study objectives, which are the purposes for performing a modeling exercise. The technical details that enter into a conceptual model will depend on both objective and subjective scientific judgments of the modeling professionals involved. The final conceptual model developed will depend on how the various transport modeling technical issues are addressed. Codes should be selected to describe the physical and chemical processes identified in the conceptual model as acting at a particular burial site. The only way that a user can be certain that selected codes are appropriate and will operate properly is through an active and rigorous evaluation using test cases. Test cases may consist of either analytical solutions to the fundanental process descriptive equations or experimental data describing the actual behavior of processes. The selection of appropriate codes cannot be considered a success until it is demonstrated 
that simulation results, derived from applying the chosen codes along with site-specific data, address the intended study objectives. This viewpoint for developing a successful site-specific simulation model was broken down into nine key steps, which form the operational approach of these guidelines. Completion of those steps will result in the development of all interrelated components of a systems simulation model, including the relevant codes.

Some specific advice for managers and site operators on how to direct a modeling exercise is based on the following five steps:

1. Identify specific questions and study objectives.

2. Establish costs and schedules for achieving answers.

3. Enlist the aid of professional model applications group.

4. Decide on approach with applications group and guide code selection.

5. Facilitate the availability of site-specific data.

These five steps for managers/site operators are discussed in detail following an explanation of the nine systems model development steps, which are presented first to clarify what code selection entails. 
CONCLUSIONS AND RECOMMENDATIONS

Some general conclusions related to the use of these guidelines are

- No single code covers all problems. This means that no single code currently available includes all processes and subsystems required to describe a low-level waste burial site. A number of codes need to be joined (coupled) to form a systems model for a burial site. An adequate generic code to cover all low-level waste management needs is not currently feasible. A generic code approach forces the representation of processes and subsystems to be over simplified and is not scientifically defensible.

- Code selection is site specific. These guidelines emphasize that code selection must be site specific to meet varying study objectives and to make appropriate use of available site characterizing data.

- Code use is modeler dependent. This means that predictions will be modeler dependent, even when the same codes are used. Different users will apply the same codes in different ways, depending on how a simulation problem is conceptualized. Conceptual models of a system will differ depending on how users address the technical issues. Technical issues will arise at each decision point out of questions as to what modeling approach is appropriate. Technical issues stem from every attempt to simplify the conceptual picture of a real burial system; therefore, modeling results depend on how the technical issues are addressed by a particular user.

- Code selection may be iterative. This means that code selection may have to be repeated for each new, changing study objective or to accommodate modifications of the conceptual model as additional site characterizing data are incorporated. The best way to implement an iterative selection may be to modify or extend available and familiar codes, rather than reselect entirely new and unproven ones.

- Code selection demands technical evaluations. A successful code selection demands that presumed simulation capabilities (modeled 
processes) be proven to work properly. At least every capability to be applied in a particular study should be tested. Technical evaluation involves rigorous testing of codes. Testing is accomplished through comparison with analytical solutions of the governing equations or actual experimental data. Testing is necessary because codes often do not operate as claimed.

To overcome the costly and time-consuming effort of code evaluation, it is recommended that well-established codes with a long-standing success history be used. This recommendation is particularly pertinent to inexperienced users.

A further recommendation for use of these guidelines derives from the following observation. A major concern of the National Low-Level Waste Management Program is the attainment of comparability for systems models applied to different burial sites. The various systems models developed to provide a performance assessment for either humid or arid sites should eventually reach a common level of predictive reliability. This is necessary to achieve consistency in making site-specific management judgments on the safety of operation. These guidelines present a clear view of how such comparability could be attained. A basic group of codes, which are generally applicable to various hydrologic transport modeling problems, should be selected and evaluated to establish their composite simulation capabilities. Also, plans for coupling those codes according to the conceptual models for a variety of low-level waste burial scenarios should be devised. This group of tested codes should be provided with ideal documentation and made available to the public. Burial facility managers and operators could then focus efforts on gathering site characterization data for the scenarios and associated study objectives. Finally, a program for developing modeling reliability assessment procedures should be sponsored. The purpose would be to provide mathematical technology and computer codes for estimating predictive confidence limits, including all aspects of modeling uncertainty. This program would provide the essential common measure of comparability. 
MODELING NEEDS

Computer simulation models are needed to organize and analyze site characterization information in order to make decisions about the operational safety of low-level radioactive waste burial facilities. Simulation models are required to focus the multitude of complex technical considerations involved in the decision-making activities associated with low-level waste management. As scientific tools, the needed simulation models must be reliable and credible representations of burial sites and their behavior. Simulation models are needed to assess every pathway for possible escape of radioactive wastes from a burial site. However, because ground water was identified as a major environmental pathway (Jacobs et a1. 1980), this report is devoted specifically to ground-water transport modeling.

The ground-water transport modeling needs for low-level waste management are diverse. To manage low-level wastes, simulation models are needed to perform initial screening of possible sites, assist in the design of burial schemes and trenches, assess the probable containment performance of specific sites, aid in the design of site monitoring programs, and predict actual waste migration when an environmental release occurs. These modeling needs comprise some typical modeling objectives. Such diverse objectives often call for many different kinds of systems simulation models with corresponding diverse theoretical complexity.

Computer codes (programs) are needed to build the systems simulation models required to represent a complicated waste burial facility. A systems model is usually composed of many computer codes representing various subsystems and their associated physical and chemical processes. No single computer code can presently meet all low-level waste management modeling needs. The interfacing of different codes is usually necessary to describe the various interacting subsystems. Totally unified and simplified generic systems models may be needed to compare the relative merits of potential sites, which involve either humid or arid hydrology. On the other hand, detailed and mechanistic 
systems models may be required to predict contaminant concentrations under specific ground-water flow conditions in order to assess actual environmental impact.

Low-level waste burial site operators and managers are confronted with a seemingly vast variety of codes, which are potentially useful for performing a ground-water contaminant transport study. There are many publications (e.g., Bachmat et a 1. 1980) that provide an inventory of available codes. Such code inventories present a confusing array of possible choices. Site operators and managers, nevertheless, need to know which codes might be appropriately selected for application to low-level waste disposal problems. 


\section{PURPOSE OF GUIDELINES}

This report provides guidance for the selection and evaluation of groundwater transport models to be used to assess the safety of a waste burial site. The guidance given here is primarily directed toward an applicationsoriented user of a computer simulation model. But the information presented here is also important to a site operator or manager who will have the responsibility of coordinating the steps involved in accomplishing a successful modeling exercise, which will ultimately carry scientific credibility.

In view of the diversity in typical modeling needs and objectives connected with low-level waste burial site management, these guidelines are formulated as a general plan for selecting relevant ground-water transport codes. They are not intended to serve as an absolute set of regulations for accepting or rejecting codes for possible use in evaluating a low-level waste management problem. Instead, the guidelines deal in general terms with groundwater transport modeling methodology; they do not give specific advice on what constitutes the "best" codes for a particular study.

These guidelines deal only with the selection of existing codes, not with the development of numerical algorithms for constructing new codes. This latter mathematical subject is beyond the scope of this report. Moreover, this report will identify certain technological weaknesses in ground-water transport theory, but it does not recommend specific future research directions. 


\section{THE CODE SELECTION APPROACH}

To build a systems model of a waste burial facility, appropriate computer codes must be selected. Code selection for purposes of modeling subsurface contaminant migration is actually a problem of developing a relevant systems model to represent the particular burial site and ground-water system. Code selection, however, is just one aspect of developing a systems model as outlined in the following ideal development steps:

1. Define site study objectives.

2. Collect and analyze site characterizing data.

3. Formulate the conceptual model.

4. Identify process descriptive equations.

5. Select the computer codes.

6. Couple/interface the selected codes.

7. Evaluate code performance.

8. Run site-specific simulations.

9. Compare results with study objectives.

The above nine steps will form the basis of these guidelines for code selection and evaluation. Code selection cannot be successfully accomplished without regard for the overall simulation model that will achieve the study objectives (step 1), and an active evaluation of code simulation capabilities (step 7) is necessary to ensure a proper selection. As shown in figure 1, these steps are involved in the development of each component of a systems model for a specific burial site. A conceptual model based on the site characterization data and consistent with study objectives is the hub of a systems model. Other systems model components are arranged as a wheel on that hub. Clockwise progress around the wheel, following the nine steps, is required to complete the systems model. During the development of a systems simulation model, the hub may require repeated modifications and revisions to produce a well-rounded and balanced wheel. These nine steps are each explained briefly below. The steps and their relationship to ground-water transport modeling are discussed in greater detail in Volume 1 of this document. 


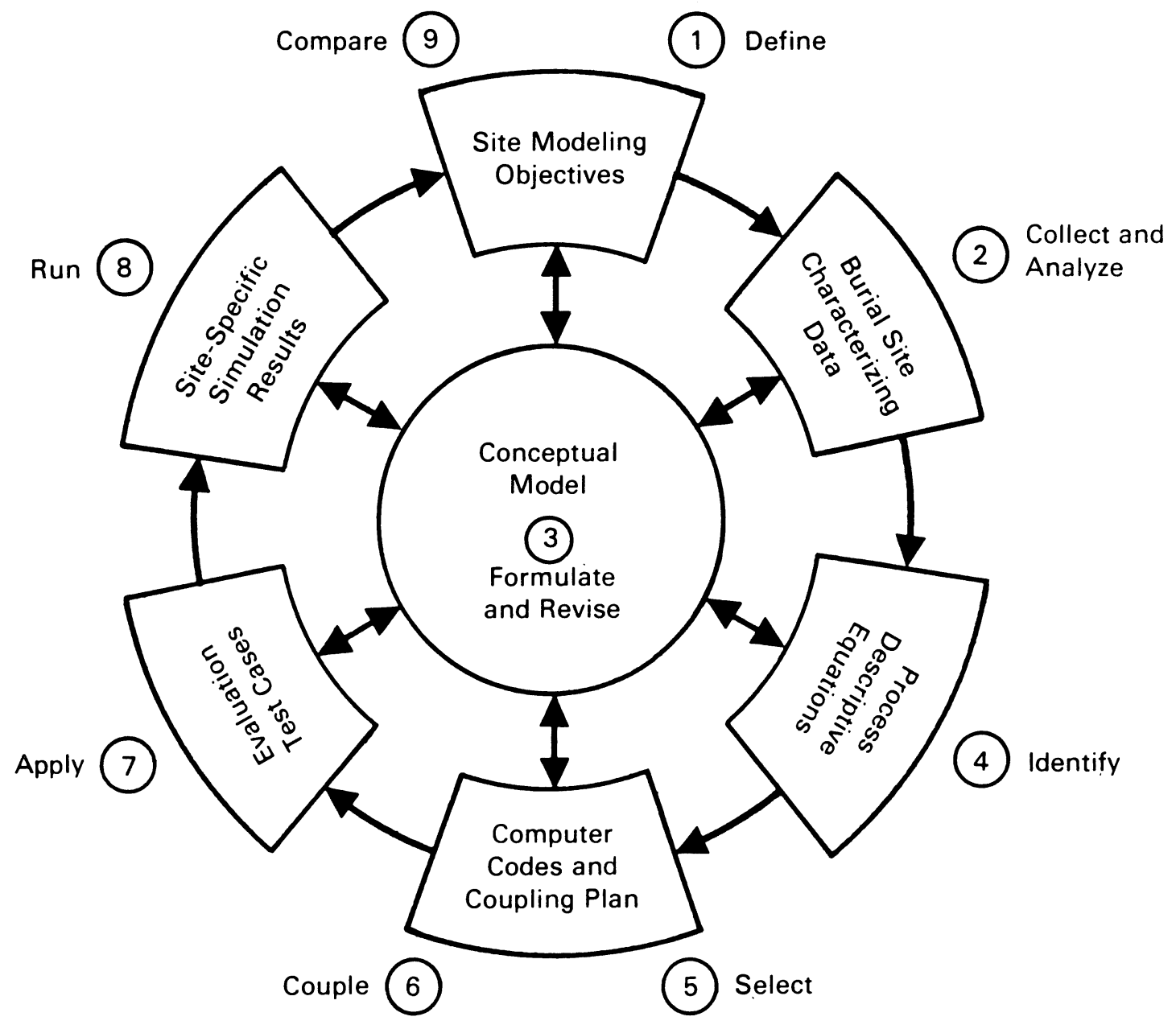

FIGURE 1. Systems Model Components. Arrows show direction for completing the systems model development steps (numbers).

\section{STEP 1. DEFINE SITE STUDY OBJECTIVES}

The study objectives are the purpose for performing a simulation of a burial system. Some common study objectives for low-level waste management are listed below:

- preliminary screening of potential geohydrologic sites for locating a burial facility

- site safety assessinent for confinement of radioactive wastes: a potential biosphere impact analysis

- site performance assessment based on existing burial system design 
- assessment of actual environmental impact: prediction of contaminant migration and dose modeling

- optimal control of contaminant migration plume in a ground-water system: design of a mitigation strategy

- site monitoring and surveillance network design.

These study objectives constitute some typical concerns of site operators and managers who would use modeling simulation results as a basis for making decisions.

The site modeling objectives indicated in Figure 1 are in a sense only a subset of the overall study objectives, because some objectives might not require examination by means of a simulation. Specific questions to be addressed by numerical simulation of a burial site have to be deduced from the study objectives. For instance, a modeling objective might be to estimate the concentration of a particular contaminant at a specific aquifer location, as observed through a sample well over some future period. A related modeling objective might then be to project the cummulative biological dose associated with water drawn from that sample well. The original study objective might have been to provide an environmental impact assessment. Thus, modeling objectives are just more explicit and detailed questions, originating in the study objectives.

The complexity of a particular study objective determines the degree of modeling sophistication required to attain relevant answers to the questions posed by a transport assessinent problem. A study objective may call for either a near-or far-field transport analysis or, perhaps, both. The appropriate codes will then depend on the kind of transport analysis required.

\section{STEP 2. COLLECT AND ANALYZE SITE CHARACTERIZING DATA}

After establishing study objectives, a modeler should proceed with assembling all information necessary for forming the conceptual model and gaining a preliminary view of how the burial system may function. These data include all dimensional measurements that describe the burial site and engineered trench facility. The data should also include the following: 
regional geologic and hydrologic maps, climatological records, hydrologic property measurements, and an inventory of waste forms. These data must be complete enough for a modeler to formulate a technical representation (i.e., initial and boundary conditions) for the burial system and for those mechanistic processes that contribute to contaminant migration. The guidelines includes a more detailed description of typical data requirements.

A report by Lutton et al. (1982) describes the typical parameters needed to characterize a low-level waste disposal site. Table 1 provides a list of those parameters. Jones and Gee (1984) discuss the specific parameters that would be required to model a shallow-land burial system at an arid site. The general group of processes that must be described at a shallow-land burial site are shown in Figure 2. Relevant parameters associated with each process model are indicated in Figure 3. A complete systems model for a shallow-land burial site would incorporate all of those process models in order to account for an accurate water balance.

The collection of site characterization data does not have to be absolutely complete before proceeding with further steps in the model development

TABLE 1. Common Parameters for Characterizing Low-Level Waste Sites

\begin{tabular}{ll} 
General & Geochemical \\
\cline { 2 - 2 } Waste-site interface & Ion exchange capacity \\
Limit of extended site & Soil pH \\
Point positions & Soil solubles \\
Material zone boundaries & Surface water chemistry \\
Geologic characteristics & Ground-water chemistry \\
Hydrological & Geotechnical \\
\hline Hydraulic conductivity & Classification \\
Anisotropy & Compaction relation \\
Porosity & Grain-size distribution \\
Hydraulic potential & Density \\
Flow direction & Strength \\
Hydrodynamic dispersion & \\
Water-holding parameters & \\
Water content & \\
Precipitation &
\end{tabular}




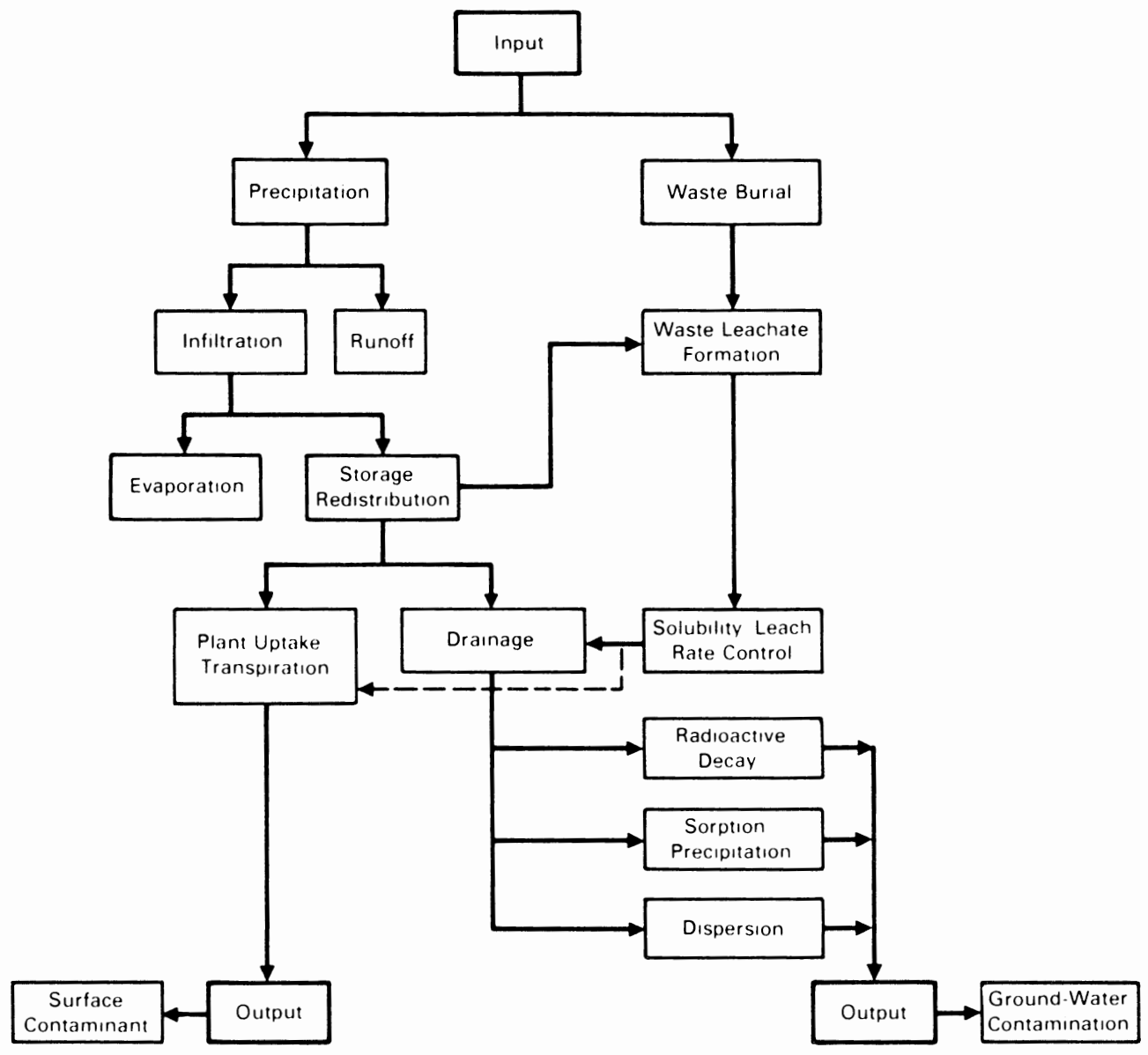

FIGURE 2. Summary of the Hydro-Geochemical Processes Controlling Radionuclide Transport at a Shallow-Land Burial Site (after Jones 1984)

plan. In fact, the data base may need to be continually supplemented as the model development steps are applied. Formation of the conceptual model, identification of process descriptive equations, and the selection of computer codes will usually point out specific data deficiencies that must be filled in to accomplish simulation runs consistent with the study objectives.

STEP 3. FORMULATE THE CONCEPTUAL MODEL

The conceptual model is a picture of a burial system (e.g., see figures 4 and 5 ), but it does not remain static. Basic site characterization data in conjunction with the study objectives (step 1) are needed to form a preliminary conceptual model, which is then progressively modified as the other planning 


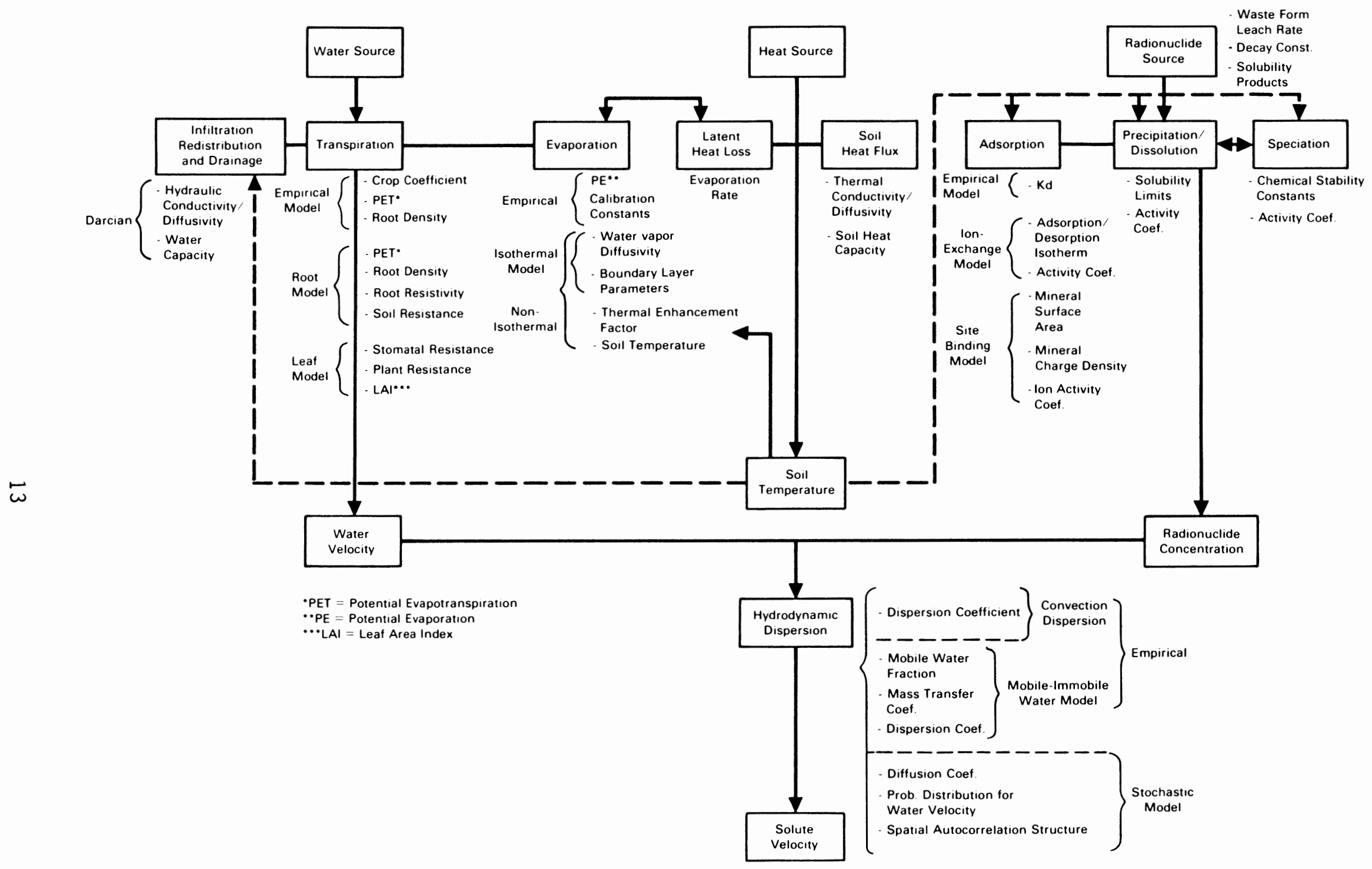

FIGURE 3. Summary of Process Models and Their Parameter Requirements, Used to Predict Unsaturated Zone Transport at a Shallow-Land Burial Site (after Jones 1984) 


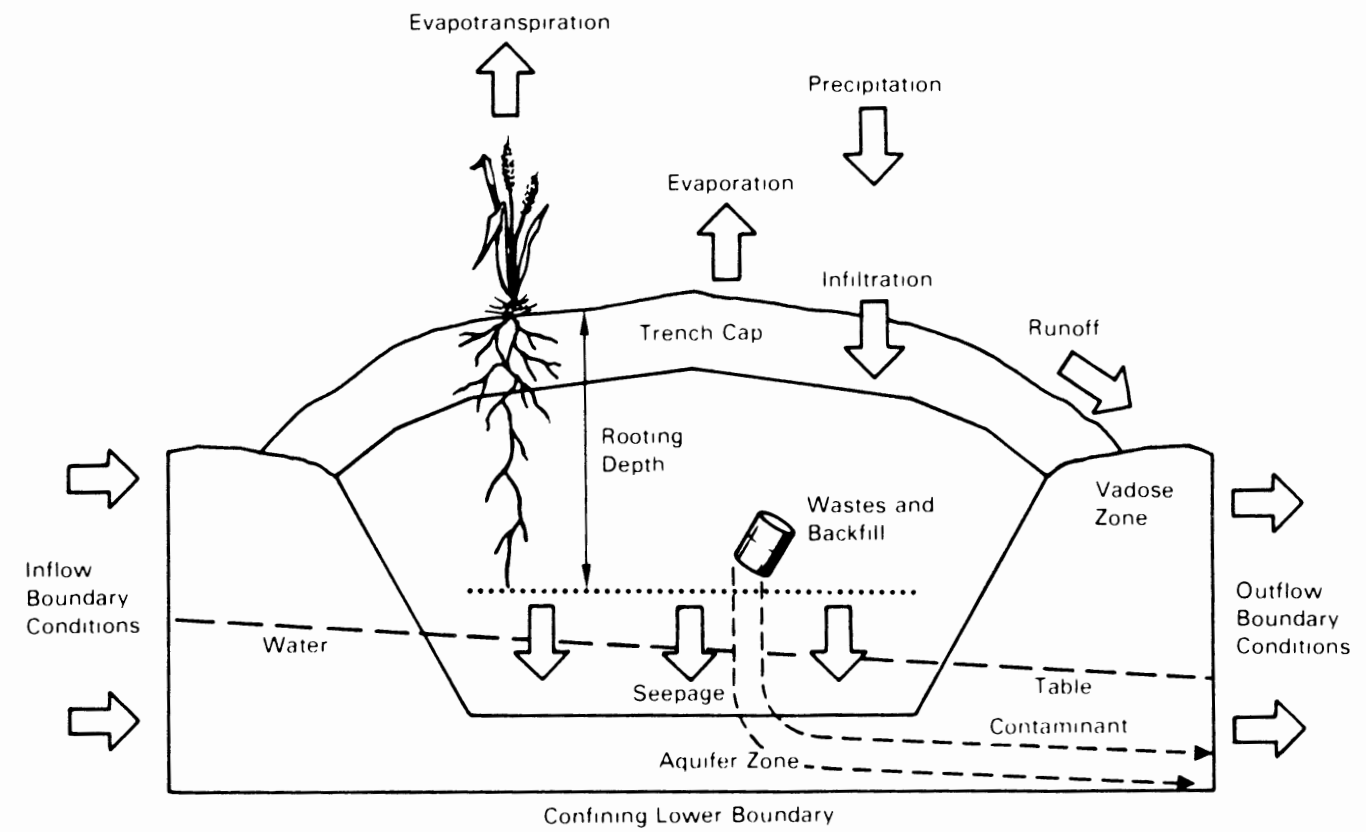

FIGURE 4. A Near-Field Conceptual Model: Hydrology of the ShallowLand Burial Trench

steps of Figure 1 are applied. For instance, the conceptual model may have to be simplified if burial site data are inherently limited or if available code technology is not adequate to simulate the initially perceived system's complexity. On the other hand, the study objectives and the conceptual model believed most appropriate may dictate the further collection of site characterization data or even the development of improved computer codes.

For purposes of systems simulation, the conceptual model is a simplified, yet rigorously technical, picture of the burial system. That picture must be technical enough in terms of fundamental processes (e.g., Figure 2), initial and boundary conditions, external hydrologic and climatic influences, and contaminant sources and sinks to determine unique predictions for a specific burial system. This is to say, a unique solution to the mathematical problem embodied in the appropriate process descriptive equations (step 4) must be achieved. The detail that enters into a conceptual model should represent the site characterization data base that is actually used in the final computer simulation model. 


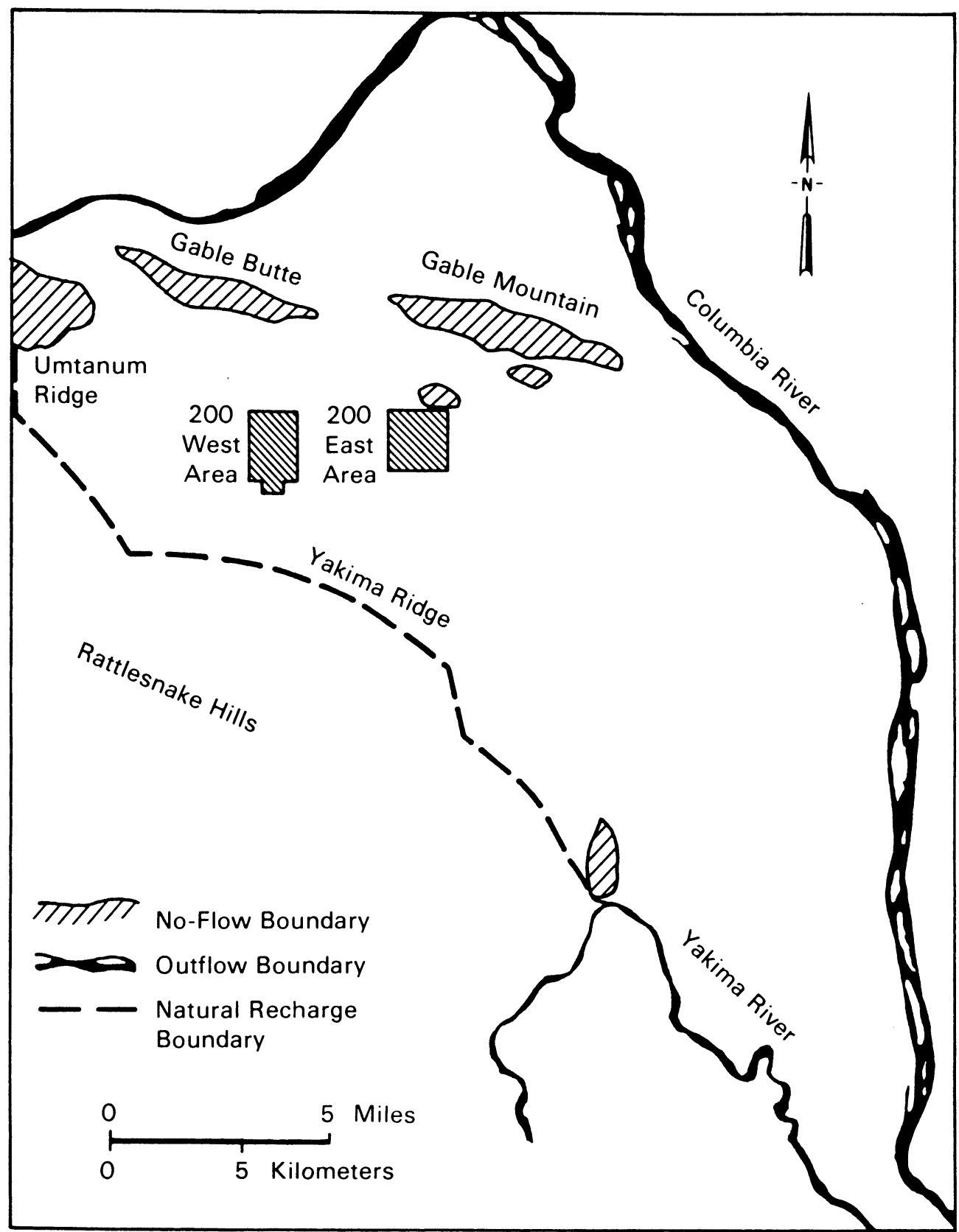

FIGURE 5. Hanford Site Unconfined Aquifer Boundary Showing the 200-West and 200-East Waste Burial Sites (after Ahlstrom 1977) 
Figure 4, for example, is a picture of a hypothetical near-field conceptual model of a shallow-land burial system. The viewpoint is cross sectional. Part of a far-field conceptualization is shown in Figure 5. The viewpoint is now areal. Both Figures 4 and 5 constitute a two-dimensional viewpoint of a burial site. Figure 5 is the region over which tritium migration was modeled (Ahlstrom et a1. 1977; Arnett et a 1. 1977). These reports together are essential for understanding all aspects of the conceptual model associated with figure 5. An interested reader is referred to those reports to complete this example conceptual model.

The conceptual model, no matter how technically complex, will always be a simplified picture of the real burial system. Current computer technology and data-gathering capabilities simply do not allow a real ground-water system and burial facility to be described in every detail. To form a sufficiently accurate simplified picture, certain ground-water transport modeling technical issues must be considered. The technical issues are simply questions as to what constitutes the correct way to describe the modeled system. The issues stem from limitations on current physical and chemical theories and computer modeling capabilities. In many cases the technical issues do not have absolute resolutions (i.e., answers).

Many of these technical issues are discussed in the guidelines, because their treatinent will determine the modeling outcome and predictions. For instance, an issue associated with the modeling described by Ah1strom et al. (1977) and Arnett et a1. (1977) might be the question: "Is a two-dimensional areal description of transport adequate?" In a general context, the answer clearly depends on the simulation study objectives and whether or not one believes that a three-dimensional process is ever reasonably represented by a lower spatial dimensionality. In the case of the study by Ahlstrom et al. (1977) and Arnett et a1. (1977), the answer seems affirmative, in view of the large areal extent, when compared with the aquifer thickness involved. In this example, issues about field-scale dispersion, however, are probably unresolved. 


\section{STEP 4. IDENTIFY PROCESS DESCRIPTIVE EQUATIONS}

Process descriptive equations are the fundamental mathematical equations required to represent those physical and chemical processes appearing in the conceptual model (e.g., Figure 2). The appropriate equations need not be expressed in any greater generality than will be necessary to implement the conceptual model.

A common practice is to begin with the most general form of applicable mathematical theory, and then, by assuming various simplifications that are compatible with the conceptual model, to reduce the complexity of the general equations. This is a deductive logical approach; an inductive approach, however, is just as valid. This means that sufficiently general equations can just as well be derived, while limited in context to the conceptual model. Moreover, it is possible in some cases that processes might be described only in terms of numerical algorithms, not explicit equations.

Site characterization data must be sufficient to define all necessary parameters (e.g., Figure 3) appearing in the appropriate descriptive equations or algorithins. For simulating contaminant migration, these equations must describe ground-water flow, solute transport, and chemical behavior in the particular porous medium. However, many equations involving other system aspects such as runoff, evapotranspiration, biological processes, and dose calculations may also be required to complete a systems inodel.

Commonly, the subprograms that appear in a computer code are concerned with solving each of the various process descriptive equations. The linking of such subprograms often represents the coupling of basic subsystems of a total systems model (e.g., Figures 3 and 6 ).

A user who is not an expert in ground-water transport theory may have to rely on a code developer's documentation report and user's guide when identifying the relevant basic descriptive equations. For such a user, the matching of fundamental processes appearing in the conceptual model with reported code capabilities will be necessary; this is the next step. A user should at least be able to identify the basic processes acting at the specific site. 


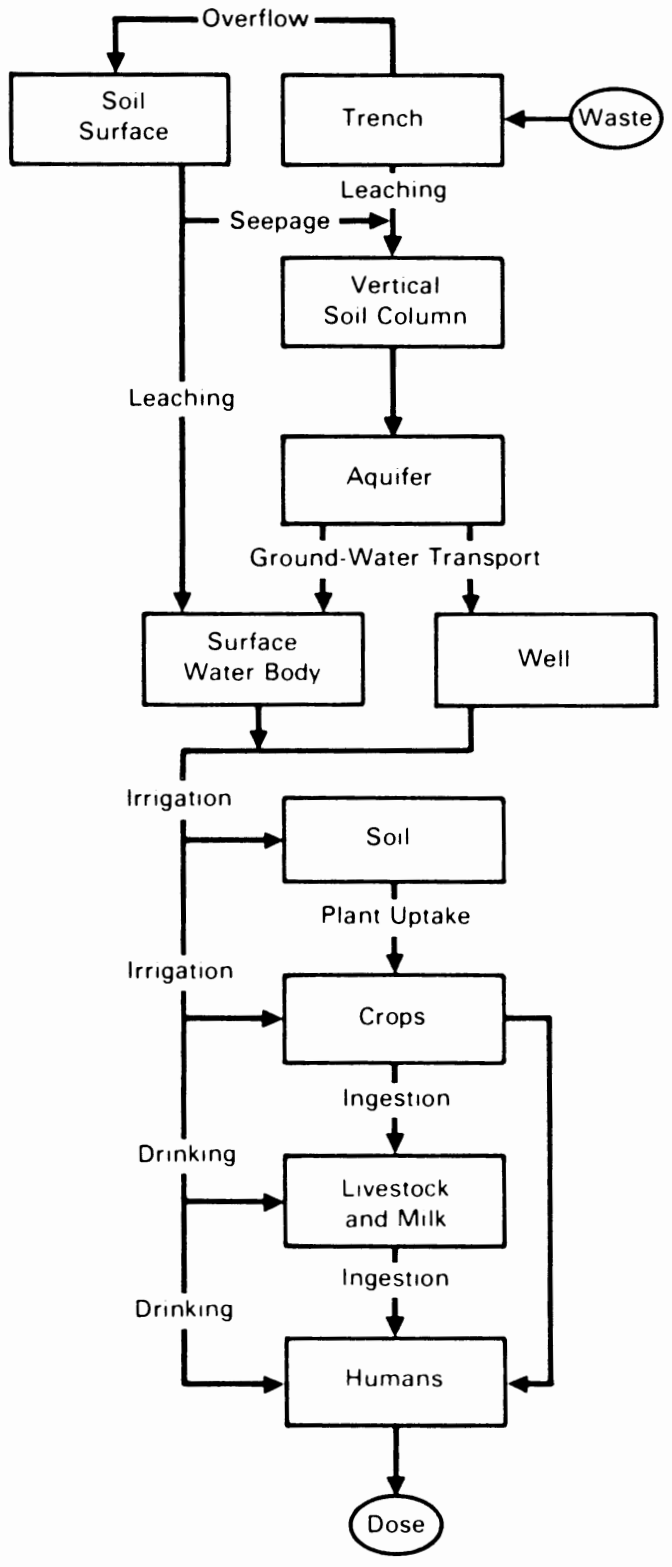

FIGURE 6. A Coupling Plan: Environmental Transport Pathways

STEP 5. SELECT THE COMPUTER CODES

This step is the primary purpose of the guidelines. Codes are simply the computer language algorithins for obtaining numerical solutions to the process descriptive equations, when site characterization data (Table 1) have been converted into the required input parameters. 
Having identified all appropriate process descriptive equations, or at least having identified the basic processes (e.g., Figures 2 and 3 ) believed to be involved, the kinds of codes required are nearly determined. In principle, a search through code summary reports (e.g., Bachmat et al. 1980) and specific code documentation (see guidelines for example codes) will help identify those codes that are potentially applicable. The potentially useful codes need only include the relevant processes. In some cases a relevant code may be so general that it needs only to be restricted to solve the special case of interest. For instance, a three-dimensional ground-water flow code should be able to solve a restricted two-dimensional problem. But an application of the more general code may be rather inefficient or even present difficulties in obtaining simulation control, as a consequence of insufficient data.

In some cases, a user may unfortunately misuse this code selection step by attempting to force fit the conceptual model or even the study objectives into the mold of a pre-chosen code. This may be successful provided the selected codes are general and flexible enough, but an unnecessary amount of model preparation effort may result. A user should avoid such modeling overkill as much as possible, especially when site information does not justify a complicated analysis. Application of a complicated code may demand further collection of site data and refinement of the conceptual model. The study objectives, however, may not warrant the extra effort.

The key aspect that a user should keep in mind when selecting a code is whether relevant evaluations of code capabilities have already been performed. Evaluation test cases should be used to prove every capability to be applied. Quite often, for various technical reasons, a code may fail to operate as claimed in a documentation report. Evaluation test cases discussed in step 7 are special example simulations of the basic processes. They are often used to verify or validate modeling capabilities. Such test cases establish how much confidence a user has in a code's ability to achieve its intended purpose. A more advanced code, which has not been sufficiently tested, can actually place a greater burden on a user who will have to test run the selected code himself, instead of relying on a developer's test cases. 
Proper code selection, therefore, depends critically on a careful evaluation of needed capabilities. An evaluation of the unified systems mode 1 being developed for treating a particular problem, however, cannot be accomplished without having a plan for code coupling or interfacing. When more than one code is involved, the code coupling plan (step 6) needs to be considered in conjunction with this step. This is why steps 5 and 6 are shown together as a single component in Figure 1.

Previous cited examples that are pertinent to this discussion are the transport simulations performed by Ahlstrom et al. (1977) and Arnett et al. (1977) which coupled a ground-water flow code with a solute transport code to model tritium migration.

\section{STEP 6. COUPLE/INTERFACE THE SELECTED CODES}

When more than one code is required, the selection step 5 must actually take into account a plan for how the needed codes will be joined together (coupled) to solve the entire systems simulation problem. Codes that pass numerical information as control data are said to be coupled. Codes that require coupling to form an entire systems model generally represent groups of processes that influence each other directly in some mechanistic way. Coupled codes may represent the relationship between parts of a systems model at either the fundamental process level or at the level of environinental pathways connecting subsystems. The coupling of processes is shown in Figure 2 , whereas a pathway coupling plan is shown in Figure 6 .

As an example of process coupling, a solute transport code must often be coupled with a ground-water flow code to perform a transport simulation. The prior computed ground-water flow is passed on to a solute transport code, which then calculates concentration and migration pattern.

A user may be able to find codes that already have the required coupling, but separation (decoupling) of the component codes that comprise the systems model can be helpful for testing each code independently. Then, if a particular code fails to meet the necessary capabilities, it can be replaced without having to rebuild the entire systems model. How strongly codes must be 
coupled depends on the interdependence of the involved processes. Codes describing processes that are linked in a reciprocal way may not allow decoupling. For instance, a strongly coupled relationship may be required to model spatial and temporal variation of chemical reactions occurring in conjunction with flowing ground water. In this case, a code that computes transport for each chemical species in a unified way may be needed, and decoupling may not be possible.

The decoupling of codes also allows for an efficient and flexible, sequential approach to simulating contaminant transfer along a system's pathway connections, as shown in Figure 6. Each code can then represent an identified part of a conceptual systems model. Figure 6 is an example of a logical flow diagram for the interconnections between parts of a systems model; in this figure, the coupling interconnections represent actual environmental transport pathways for contaminant transfer. The coupling plan in Figure 6 was used by Hung et al. (1983) to accomplish dose calculations. Such calculations give an estimation of final human dose as a consequence of a specific radioactive waste input.

To reach an objective of assessing health effects, the generic systems model described by Hung et al. (1983) seems to allow a user a way of circumventing the rigors of these first six modeling steps. However, without a careful evaluation as discussed under step 7, there is no assurance that model predictions would be relevant or accurate for a specific burial site.

The main technical difficulty a user will face in achieving coupling is ensuring that the variables of interconnected codes are compatible. Spatial and temporal resolutions (scales) used in each chosen code must also be taken into account. In brief, code coupling is a very technical problem demanding careful treatment, and a specific reason why modeling professionals should be involved, rather than relegating coupling to a generic code.

\section{STEP 7. EVALUATE CODE PERFORMANCE}

This is the critical step of systems model development, during which presumed code simulation capabilities are tested. Code capabilities are the processes that a simulation model can describe. The purpose of this step is to 
confirm that selected codes will actually work as intended. Moreover, code capabilities must be evaluated for their relevance to the system's conceptual model.

In step 5, a user should have considered codes that have al ready been tested as much as possible. In any case, all capabilities should be test run by the user and results compared with standard test cases. Evaluation test cases may take the form of analytical solutions obtained for special conditions or experimental data sets obtained for validation purposes. Test cases might also take the form of special benchmark cases (e.g., Ross et al. 1982), which are used to qualify codes for making certain performance assessments. Test cases usually represent the ideal behavior of the fundamental processes acting in the modeled system. A selected code that cannot reproduce the expected behavior of the basic, identifiable processes known to act in a system cannot provide accurate or credible predictions when incorporated into the complete systems model. Code evaluations must take into account the various groundwater technical issues discussed in the guidelines, as are relevant to the conceptual model.

Proper code evaluation can be the most costly and time-consuming part of systems model development. For this reason, a user should attempt to select codes that have already been tested in a relevant way. Code evaluation, however, is also an opportunity for a user to make absolutely certain that a code will operate as reported by a developer and a time to gain experience with applying a chosen code. Codes simply do not always perform as claimed, when applied under different circunstances. A code evaluation is thus simply a part of establishing a model's reliability, as well as prerequisite capabilities.

As a reconmendation, an inexperienced user is advised to select codes that have a long-standing history of successful applications as found in reports. Usually, this means that more evaluations have been accomplished successfully by others.

Professional user groups (ground-water modelers) usually employ a limited set of codes as their standard tools. The standard tools are usually welltested, but, of course, they represent the numerical methods bias of the group. When such standard codes do not meet an expected applications need, 
modification is the common practice. Seldom is the selection process repeated again for each new application. Thus modification or extension of code capabilities is the common approach taken. Usually it is far more efficient to build on a familiar and available simulation technology than to cast codes aside and select newer ones again. The certainty of the previously established code evaluations is what professional user groups try to maintain. In any event, regardless of how the final codes are acquired, careful evaluation is the common factor that ensures scientific consistency and proper application.

\section{STEP 8. RUN SITE-SPECIFIC SIMULATIONS}

The final component in the development of a site-specific systems model is the running of the selected codes, while using the site characterization data. At this stage the coupling plan is implemented. The codes will have been evaluated (step 7) to make certain that all the required capabilities work. The auxiliary software and methods for preparing data as input and analyzing program output are also important parts of running the simulations. Conclusions will depend greatly on how numerical output is displayed and analyzed. That aspect involving the display software and supporting analysis should be considered during the code selection (step 5) as well.

It is not always straightforward to run site-specific simulations. Adjustments and calibrations of a simulation model are usually required to make it match the known information. This is a necessary part of making a simulation model give relevant predictions about a specific system. This step is discussed further in the guidelines.

\section{STEP 9. COMPARE RESULTS WITH STUDY OBJECTIVES}

This is the last step that completes Figure 1. A modeling exercise is not finished until it is certain that original simulation study objectives are achieved. This may require a return to any previous step for modifications or adjustments to achieve site-specific modeling objectives. On the other hand, a certain study objective might be found to fall beyond the capabilities of currently available code technology or even fundamental science. In this way a modeling effort may point the direction to needed future research. The systems 
modeling effort then becomes a logical justification for further research, as well as a way of obtaining answers to specific questions.

This completes the explanation of the nine steps seen in Figure 1 . The guidelines provide a more detailed discussion of these steps and a discussion of how code documentation reports should contribute to completing these steps. 
THE GUIDELINE APPROACH

This section summarizes the role of certain concepts presented in the guidelines. Also, the entire viewpoint of the guideline is briefly reviewed. The approach of the guidelines puts the emphasis on a very general guidance-not just a sequence of steps exclusively relevant to only ground-water transport modeling.

\section{USER'S ROLE}

It is not easy to implement the nine systems model development steps discussed in the previous section. Successful code selection depends on other factors that are not apparent in those steps. In particular, much depends on the technical knowledge and experience of a user who is the modeling practitioner.

In the context of this report, a "user" is one who uses computer programs (codes) to study and quantitatively assess a ground-water contamination situation, which could be actual or expressed as a hypothetical problem. A user might also be a manager or site operator who will use simulation results to make decisions. A user who implements computer codes according to some conceptual plan for a burial facility and ground-water system is a modeler. The systems model employed by a modeler is defined here as being both the conceptualization and the associated computer codes, including the needed input data that determine a problem solution. A user obviously needs to select codes to do computer modeling. Modeling, however, does not always require the use of codes.

By current ground-water transport modeling technology, codes are at best only tools in the hands of a user practitioner, and the presently available codes simply cannot transform a computer into a thinking machine capable of giving correct answers to every question about contaminant migration.

The guidelines presume that an applications-oriented user is familiar with the scientific aspects of contaminant transport in ground-water systems, but nevertheless, reconmends certain technical background for a user; a number of documented computer codes for ground-water flow and solute transport are 
pointed out, too. The kinds of computer codes that a user could choose range from simplified, generic to complex, mechanistic ones, as discussed in the guidelines.

CONCEPTUAL MODEL

The central element of a systems simulation model, as pointed out in step 3 , is the conceptual model. A conceptual model is always a simplified picture of any actual burial facility and its hydrogeology. To put the conceptual model in place in order to develop the appropriate systems model (Figure 1), a modeler must also address the technical issues. Technical issues are just questions about how to proceed with ground-water modeling, recognizing that current predictive technology has inherently limited capabilities.

To select appropriate computer codes, a user should make effective use of available code documentation reports. (What to look for in good reports is described in the guidelines.) Then a user should follow the nine systems model development steps.

\section{CODE EVALUATION}

The main idea emphasized in the guidelines is that successful systems modeling depends on carefully evaluating code capabilities and selecting codes that are compatible with a predefined conceptual model for a particular lowlevel waste burial facility. It may occur, however, that the conceptual model requires revision as the systems model development proceeds. Moreover, the resulting computer model should be devised to answer specific questions about the system's behavior, stated clearly as the study objectives. This is the reason why most of the guideline stresses the use of evaluation test cases to prove code capabilities for processes that need to be described. The explicit application of this viewpoint was exemplified by the model development efforts of Kincaid et al. (1984a,b). A similarly extensive effort would be required to select codes to model low-level waste burial sites. 


\section{CODE SELECTION}

A systems model developed for a certain purpose should not be expected to apply directly to another purpose. For instance, a simplified generic systems model used to examine the interrelationships of processes acting in a waste burial system should not be expected to provide accurate site-specific predictions of contaminant transport, even if site-specific data are input. Also, a preselected code should not determine what site characterization data are sufficient to model a specific burial site. It is the acting processes identified in the conceptual model that determine which codes and data are needed.

The correct simulation model used to analyze a particular problem is not simply predicated on what constitutes the most powerful equation-solving approach. The main concern of the guidelines is proper modeling of the relevant physical and chemical processes. Therefore, a user will notice that the guidelines do not dwell on the mathematical details of various equationsolving methods, although this is an unavoidable part of transport modeling. The view here is that any computer algorithm that is sufficiently accurate to meet a user's study objectives, as judged by comparison with evaluation test cases, is acceptable. Computational efficiency and computer resource requirements are seen here as the user's responsibility, and the guidelines are only concerned with the scientific, rather than economic, considerations of code selection.

This means that new codes do not have to be reselected to treat each new problem. Available and familiar codes, as long as they are appropriate, may be modified to include the necessary simulation capabilities, provided that proper evaluation is done. It is sometimes easier for a modeler to extend a familiar code's capabilities than to begin with a reportedly advanced code that has not been adequately tested, or may even present unknown simulation control difficulties. 


\section{GUIDANCE FOR MANAGERS AND SITE OPERATORS}

In this section the role of a manager or site operator who is involved in the code selection and systems model development process is discussed. Perhaps the major concern of a manager is the selection of codes that can be used to accomplish a burial site performance assessment. Such an assessment may be required to identify potential waste burial sites or to evaluate the performance of an existing facility. Associated with this range of study objectives, there may be different levels of complexity in the site characterizing information available to accomplish a modeling effort. Therefore, different codes may be appropriate for addressing those diverse study objectives.

It is unlikely that a manager can select appropriate codes without the assistance of technical professionals. Moreover, code selection will not be a one-time activity that remains adequate for all future modeling needs. What a manager/site operator needs to know, therefore, is how to direct a successful application of the nine steps shown in Figure 1.

The most important attitude that a manager should keep in mind is that "models are to be used as decision-making tools," as stated by Large (1980). Answers derived from modeling cannot be used to replace good management judgments. Predictions and projections obtained from models should be used to support study conclusions--not to determine them in an absolute way based on whether or not results fit within criteria. A careful and extensive examination of model reliability is needed before a model's predictive accuracy can be trusted.

The belief that use of the "best" or most mathematically advanced codes will automatically provide reliability and scientific credibility is false. It is the capability of technical professionals who will be involved that has the greatest impact on overall confidence attained. Selection of the codes for a particular study is not difficult--but proper use often is. Outstanding codes tend to be quickly recognized and implemented by professional ground-water modelers. But managers need to make certain that they are not oversold on the use of predetermined codes without considering available data and study objectives. 
STEPS FOR MANAGERS/SITE OPERATORS

The following steps are recommended for managers who will use models in a decision-making effort:

1. Identify the specific questions and study objectives.

2. Establish costs and schedules for achieving answers.

3. Enlist the aid of professional model applications group.

4. Decide on approach with applications group and guide code selection.

5. Facilitate the availability of site-specific data.

Each of these steps is explained further below.

Step 1. Identify Questions and Study Objectives

The manager will identify the actual questions about site performance that bear on the public's concern for safe operation. These questions are then reduced to the technical study objectives to be considered by modelers (step 1, Figure 1). This step cannot be effective unless the manager understands how to phrase the questions in quantitative terms appropriate to ground-water transport modeling. Bachinat et al. (1980) have discussed the problem of communication between managers and technical professionals. That discussion is very germane to low-level waste management, as well as to ground-water resource management.

Step 2. Establish Costs and Schedules

It is the job of the manager to determine how much money and time should go into obtaining the modeling results needed to make decisions. The level of study detail is limited by costs and schedules. Credibility and reliability of model results are also affected. The final cost and schedule needs to be established through agreement with the chosen technical professionals (see step 3).

The main cost in applying a model is connected with preparing data and integrating simulation results--not the cost in running a code. Run time is the actual time spent calculating numbers--not the much greater time spent to prepare data as input parameters and to interpret results. A present-day 
reality of ground-water transport modeling that a manager needs to know is that the most costly part is preparing and setting up for a simulation. The cost of actually running a code is usually only a small part. In fact, most nontrivial ground-water codes are very data hungry, and an extensive effort is needed to gather data for formulating the conceptual model and for obtaining control parameters necessary for site-specificity. A main part of a professional modeler's job is performing this data preparation task, even if a site operator is able to provide a complete list of basic information. Usually basic site information must be considerably manipulated to prepare it as code-control input data. Therefore, today, ground-water transport modeling is still very labor-intensive, and the coordinated efforts of many individuals with specialized training (e.g., geologists, hydrologists, soil physicists, numerical modelers) are needed to accomplish a realistic ground-water transport simulation of a waste burial facility. A statistician may also be needed to include an uncertainty and sensitivity study.

As a rule, costs will escalate considerably when the modeling includes an evaluation of predictive reliability. Many repeated simulations using different parameter values or complicated uncertainty studies are necessary to establish error bounds on modeling results. Such additional efforts, however, may be necessary to establish the credibility of results for subsequent management decisions.

Step 3. Enlist Aid of Professional Modelers

A decision-making manager or site operator probably would not have sufficient personal time or expertise to select and apply the appropriate codes, so help from a professional modeling group, as found in national research laboratories, consultant firms, or universities, will inevitably be necessary. Because transport models are not currently self-contained and automated to run within a single code, without the usual technical difficulties connected with most numerical algorithms, a user must have an intimate knowledge of how to couple and control any selected codes. Thus, a manager who proceeds to select codes must first employ people to apply them.

Simplified, generic systems models, which are self-contained, have been developed to bypass this dependence on the capabilities of a specific modeling 
group. Such models are also applied in an attempt to achieve comparability in the analysis of different burial facilities. This approach by its very contrivance, however, does not allow for the flexibility needed to make sitespecific management decisions. The principal attractiveness of the generic code approach seems to be that a dose-to-man calculation is easly incorporated to arrive at a direct evaluation of environmental safety. Without careful code calibration and validation of the system representation, however, there is no reliability that such a model represents any specific burial facility. In brief, a generic modeling approach cannot be trusted, unless applied with a clear understanding of all inherent representational limitations. This means that a generic model should be fully documented to clarify conceptual limitations before being applied by inexperienced users. In any case, a generic model needs to be qualified by applying the same steps for developing a sitespecific model for each study.

A present-day fact, however, seems to be that the biases of a particular user group determines the choice of codes to be used. This means that modeling groups tend to apply codes that are familiar. Unfortunately, such bias can limit the relevancy and accuracy of a study if the proper codes and approach are not used. On the other hand, by being prepared to apply specific codes, a professional group can often perform an efficient, economical, and timely analysis of a ground-water contamination problem. Professional groups usually maintain a core group of well-tested codes to minimize the need to perform repeated code-capability evaluations, as must be done for newly developed codes or for unfamiliar codes. Moreover, an expert modeler can often overcome code limitations, at least during the stage of providing an interpretation of final simulation results.

The most critical step for a manager, therefore, is the selection of a modeling group that will in a real sense become part of the systems model to be employed. A manager should examine the credentials of those individuals actually involved--not just the name of the research lab or consulting firm contracted. The more experienced modeler will present results in a form that simplifies drawing conclusions and making decisions. Previous model application reports are a good indicator of professional capabilities. As a rule, a 
code developer may not necessarily be the best person to rely on to accomplish an applications-oriented study, because much more than skill with numerical algorithms is needed to accomplish successful analysis of a waste burial facility.

Step 4. Decide on Approach and Guide Code Selection

A manager has to decide on how complex a modeling effort should be in order to draw sufficiently accurate conclusions for making decisions. The available funds, time, and potentially available site characterizing data will all constrain the achievable reliability of modeling results. Agreenent with the professional group is necessary to determine an approach that best fits cost and schedule constraints.

The technical professionals should help decide if the modeling approach should be a simplified one or involve a detailed simulation. A possible decision might be that no computer code is needed, and a simple analysis of site data is sufficient to draw a conclusion. A manager should beware of being oversold on the idea that every problem requires use of a complicated code. In deciding on an approach, a manager should consider the complexity of the environmental dose calculation that will be performed in conjunction with the contaminant transport study. The particular dose code employed may have no options for using a detailed spatial and temporal description of contaminant dispersal. A complicated transport analysis may then be useless or, at least, unnecessary.

A manager should guide the code selection process according to the nine steps previously suggested for an applications-oriented user. A manager needs to be certain that the code selection is pertinent to the agreed-on approach and will efficiently meet the original study objectives. For this reason, a inanager should not simply assign the job and then walk away. Various kinds of technical difficulties may be encountered while following the steps in Figure 1, and a manager may have to take part in the decisions on how best to proceed. In fact, while arriving at modeling results, the conclusions based on professional judgments for each decision-making step should be documented. Documentation of the steps in Figure 1 will provide quality assurance and support a determination of reliability. 


\section{Step 5. Facilitate Availability of Site-Specific Data}

To make certain that systems model development proceeds efficiently and effectively, a manager should continually see to it that the modelers receive necessary data. Generally, complete and adequate data cannot be provided at the outset. Additional data may be needed in the conceptual model formulation, code evaluation, and site-specific simulation stages of Figure 1.

In choosing an approach (see step 4), both manager and modeler should keep in mind that the predictive accuracy of a transport simulation is severly restricted by how well the contaminant source is characterized in terms of the involved chemical properties and release rates. No transport code--regardless of general capabilities--can compensate for an unknown source description. A manager or site operator cannot expect an accurate estimation of migrating contaminant concentrations without first providing accurate data on the waste sources involved. At the same time, a modeler should not treat the release description in a trivial way, if a defensible prediction is the study objective.

\section{MODEL RELIABILITY}

A major concern of a manager/site operator is indeed the predictive reliability of modeling results. Predictive reliability is a terı for describing the confidence assignable to a performance assessment. As defined here, a performance assessment is an analysis and evaluation of a waste burial system's ability to conform with regulatory performance criteria. A perforinance assessment involves predicting the potential radiological impact of a waste disposal system, taking into account all natural and engineered components of the system.

Most recent advances in hydrologic transport modeling stem from efforts to quantify predictive reliability. In particular, the subjects of stochastic hydrology, parameter sensitivity analysis, and uncertainty analysis all contribute to a determination of predictive reliability (confidence limits). But these subjects can only be applied to quantifiable uncertainies, expressed in terins of statistical parameters and specific, predefined systems models. In other words, the variation in simulation results taken over all potentially 
appropriate descriptive systems models can not be easily evaluated. Bounding estimates based on conservative modeling approaches are usually required to guage the uncertainty and predictive reliability questions.

The main impediment to making hydrologic transport predictions is the unknown hydrogeologic structure beneath the ground surface. The uncharacterized heterogeneous nature of the underground places inherent limitations on predictability of contaminant migration behavior. This technical difficulty is discussed further with the issues pointed out in the guidelines. There are many hydrologic transport modeling aspects, such as incompletely described processes (e.g., field-scale dispersion, chemical-media interactions) and the limited measureability of hydraulic properties, that contribute to predictive uncertainties. A manager needs to be familiar with these difficulties and take them into account in making judgments based on modeling results.

\section{A RECOMMENDATION FOR RELIABILITY}

Presently available hydrologic transport codes do not incorporate an estimation of uncertainty bounds. Estimation of uncertainty bounds for modeling results must be done through applying a variety of external code manipulation procedures (i.e., parameter sensitivity and error propagation studies). A great deal of specialized knowledge is required to accomplish such studies, and this fact constitutes another chief reason why a capable professional modeling group should be involved in a burial site simulation study. A manager/site operator who expects to have to defend decisions based on modeling results should strongly consider including a competent reliability analysis. Such an analysis will be a final determination of whether or not code selection for meeting specific study objectives was successful. 
REFERENCES

Ahlstrom, S. W., et al. 1977. Multicomponent Mass Transport Model: Theory and Numerical Implementation (Discrete-Parcel-Random-Walk Version). BNWL-2127, Pacific Northwest Laboratories, Richland, Washington.

Arnett, R. C., et al. 1977. Hanford Groundwater Scenario Studies. ARH-SA-292, Atlantic Richfield Hanford Company, Richland, Washington.

Bachmat, Y., J. Bredehoeft, B. Andrews, D. Holtz and S. Sebastian. 1980. Groundwater Management: the Use of Numerical Models. Water Resources Monograph 5, American Geophysical Union, Washington, D.C.

Hung, C. Y., G. J. Meyer and V. C. Rogers. 1983. "Use of Presto-EPA Model in Assessing Health Effects from Land Disposal of LLW to Support EPA's Environinental Standards" in Proceedings of Fifth Annual Participants' Information Meeting DOE Low-Level Waste Management Program. CONF-8308106, National Low-Level Waste Management Program, Idaho Falls, Idaho.

Jacobs, D. G., J.S. Epler and R. R. Rose. 1980. Identification of Technical Problems Encoutered in Shallow Land Burial of Low-Level Radioactive Waste. ORNL/SUB-80/13619/1. Oak Ridge National Laboratory, Oak Ridge, Tennessee.

Jones, T. L., and G. W. Gee. 1984. Assessment of Unsaturated Zone Transport for Shallow Land Burial of Radioactive Waste: Summary Report of Technology Needs, Model Verification and Measurment Errors (FY78-FY83). PNL-4747, Pacific Northwest Laboratory, Richland, Washington.

Kincaid, C. T., J. R. Morrey and J. E. Rogers. 1984a. Geohydrochemical Models for Solute Migration Volume 1: Process Description and Computer Code Selection. EA-3417, V.1, Electric Power Research Institute, Palo Alto, California.

Kincaid, C. T., J. R. Morrey, S. B. Yabusaki, A. R. Felmy and J. E. Rogers. 1984b. Geohydrochemical Models for Solute Migration Volume 2: Prel iminary Evaluation of Selected Computer Codes. EA-3417, V.2, Electric Power Research Institute, Palo Alto, California.

Large, D. E. 1980. "USDOE Needs in Modeling for Low-Level Radioactive Waste Management." In Modeling and Low-Level Waste Mangement: An Interagency Workshop. Edited by C. Little and L. Stratton, Oak Ridge National Laboratory, Oak Ridge, Tennessee.

Lutton, R. J., P. G. Malone, R. B. Meade and D. M. Patrick. 1982. Paraneters for Characterizing Sites for Disposal of Low-Level Radioactive Waste. NUREG/CR-2700, U. S. Nuclear Regulatory Commission, Washington, D.C.

Ross, B., J. W. Mercer, S. D. Thomas and B. H. Lester. 1982. Benchmark Problems for Repository Siting Models. NUREG/CR-3097. U.S. Nuclear Regulatory Commission, Washington, D.C. 
1 


\section{DISTRIBUTION}

No. of

Copies

OFFSITE

W. E. Pasko

Oak Ridge Operations Office

U.S. Department of Energy

P.0. Box E

Oak Ridge, TN 37830

L. J. Mezga, Program Manager

Low-Level Waste Management Program

Oak Ridge National Laboratory

P.0. Box $X$

Oak Ridge, TN 37830

M. J. Barainca

Idaho Operations office

U.S. Department of Energy

550 Second Street

Idaho Falls, ID 83401

R. Boland

Waste Management Project Office

Nevada Operations Office

U.S. Department of Energy

P.0. Box 14100

Las Vegas, NV 89114

T. C. Chee

DP-123 (GTN)

U.S. Department of Energy Washington, DC 20545

B. W. Church, Director Health Physics Division Nevada Operations office U.S. Department of Energy P.0. Box 14100

Las Vegas, NV 89114
No. of

Copies

J. A. Coleman

NE-25 (GTN)

U.S. Department of Energy

Washington, DC 20545

J. E. Di eckhoner

DP-122 (GTN)

U.S. Department of Energy

Washington, DC 20545

C. P. Gertz

Idaho Operations office

U.S. Department of Energy

550 Second Street

Idaho Falls, ID 83401

F. Gorup

Chicago Operations office

U.S. Department of Energy

9800 South Cass Avenue

Argonne, IL 60439

J. J. Jicha

DP-123 (GTN)

U.S. Department of Energy

Washington, DC 20545

L. Lanni

San Francisco Operations office

U.S. Department of Energy

1333 Broadway

Oakl and, CA 94612

B. Lawless

Savannah River Operations Office

U.S. Department of Energy

P.0. Box A

Aiken, SC 29801

D. B. Leclaire

DP-12 (GTN)

U.S. Department of Energy

Washington, DC 20545 
No. of

Copies

D. M. Lund

Waste Management and

Transportation Development

Division

Albuquerque Operations office

U.S. Department of Energy

P.0. Box 5400

Albuquerque, NM 87115

S. Mann, Senior Program Manager

Technical Management Division

Chicago Operations office

U.S. Department of Energy

9800 South Cass Avenue

Argonne, IL 60439

C. L. Mathews

Oak Ridge Operations Office

U.S. Department of Energy

P.0. Box E

Oak Ridge, TN 37830

J. M. McGough

Albuquerque Operations office

U.S. Departinent of Energy

P.0. Box 5400

Albuquerque, NM 87115

H. Saucier

Savannah River Operations office

U.S. Department of Energy

P.0. Box A

Aiken, SC 29801

J. L. Smiley

NE-25 (GTN)

U.S. Department of Energy

Washington, DC 20545

J. B. Whitsett

Idaho Operations office

U.S. Department of Energy

550 Second Street

Idaho Falls, ID 83401
No. of

Copies

30 DOE Technical Information Center

C. S. Abrams

Argonne National Laboratory West

P.0. Box 2528

Idaho Falls, ID 83401

S. S. Borys

Argonne National Laboratory

9700 S. Cass Avenue, Bldg. 205

Argonne, IL 60439

Technical Library

Argonne National Laboratory

Argonne, IL 60439

B. Rawles

Battelle Memorial Institute

Office of Nuclear Waste

Isolation

505 King Avenue

Columbus, $\mathrm{OH} 43201$

P. Colombo

Brookhaven National Laboratory

Building 701

Upton, NY 11973

R. H. Beers

EG\&G Idaho, Inc.

P.0. Box 1625

Idaho Falls, Idaho 83415

M. J. Case

EG\&G Idaho, Inc.

P.0. Box 1625

Idaho Falls, ID 83415

R. L. Dodge

EG\&G Idaho, Inc.

P. 0. Box 1625

Idaho Falls, ID 83415 
No. of

Copies

E. A. Jennrich

EG\&G Idaho, Inc.

P.0. Box 1625

Idaho Falls, ID 83415

J. G. Couch

Fermi National Accelerator Laboratory

P.0. Box 500

Batavia, IL 60510

R. E. Anderson

Goodyear Atomic

P.0. Box 628

Piketon, $\mathrm{OH} 45661$

International Ground Water Modeling Center

Holcomb Research Institute

Butler University

Indianapolis, IN 46208

R. Brown

Idaho National Engineering Laboratory

Idaho Falls, ID 83401

Technical Library

Idaho National Engineering Laboratory

Idaho Falls, ID 83401

Chin Fu Tsang

Lawerence Berkeley Laboratory

University of California

Berkeley, CA 94720

T. Harvey

Mail Stop L-262

Lawrence Livermore National Laboratory

P.0. Box 808

Livermore, CA 94550
No. of

Copies

C. B. Ozaki

Toxic Waste Control

Lawrence Livermore National

Laboratory

P.0. Box 808

Livermore, CA 94550

W. Hanson

Los Al amos National Laboratory

P.0. Box 1663

Los Al amos, NM 87545

D. T. Oakley

Los Al amos National Laboratory

P.0. Box 1663

Los Al amos, NM 87545

J. G. Steger

Los Al amos National Laboratory

Los Al amos, NM 87545

Technical Library

Los Al amos National Laboratory

Los Alamos, NM 87545

J. McMenamin

Mason and Hanger - Silas

Mason Co.

Pantext Plant

P.0. Box 30020

Amarillo, TX 79177

R. K. Bl auvelt

Monsanto Research Corporation

Mound Facility

P.0. Box 32

Miamisburg, OH 45342

$R$. R. Jaeger

Monsanto Research Corporation

P.0. Box 32

Miamisburg, $\mathrm{OH} 45342$ 
No. of

Copies

M. W. Boback

National Lead

P.0. Box 39158

Cincinnati, $\mathrm{OH} 45239$

National Academy of Sciences

National Research Council

2101 Constitution Avenue

Washington, DC 20418

J. S. Baldwin

Oak Ridge National Laboratory

P.0. Box X

Oak Ridge, TN 37830

T. Butz

Oak Ridge National Laboratory P.0. Box X

Oak Ridge, TN 37830

$F$. Homan

Oak Ridge National Laboratory P.0. Box $X$

Oak Ridge, TN 37830

D. Kocker

Oak Ridge National Laboratory P.0. Box X

Oak Ridge, TN 37830

F. Kornegay

Oak Ridge National Laboratory

P.0. Box X

Oak Ridge, TN 37830

F. Pinn

Oak Ridge National Laboratory

P.0. Box X

Oak Ridge, TN 37830

T. H. Row

Oak Ridge National Laboratory

P.0. Box $X$

Oak Ridge, TN 37830
No. of

Copies

Technical Library
Oak Ridge National Laboratory

Oak Ridge, TN 37830

T. Jokerst

Paducah Gaseous Diffusion Plant

P.0. Box 1410

Paducah, KY 42001

E. W. Kendall

REECO

P.0. Box 642

Mercury, NV 89023

J. J. Bl akeslee

Rockwell International

Rocky Flats Plant

P.0. Box 464

Golden, CO 80401

C. E. Wickland

Rockwell International

Rocky Flats Plant

P.0. Box 464

Golden, C0 80401

E. L. Albenesius

Savannah River Laboratory

P.0. Box A

Aiken, SC 29801

Technical Library

Savannah River Laboratory

Aiken, SC 29801

0 . Towler

Savannah River Laboratory

Aiken, SC 29801

Professor $\mathrm{H}$. Wang

1215 W. Dayton Street

Department of Geology and Geophysics

University of Wisconsin

Madison, WI 53706 
No. of

Copies

G. L. Meyer

U.S. Environmental Protection Agency

Office of Radiation Programs

ANR-460

Washington, DC 20460

U.S. Environmental Protection Agency

Technology Assessment Division

Office of Radiation Programs

Washington, DC 20460

J. Fischer

Office of Hazardous Waste Hydrology

U.S. Geological Survey

410 National Center

Reston, VA 22092

D. S. Morgan

U.S. Geological Survey

705 N. Plaza Street

Carson City, NV 89701

E. P. Week s

U.S. Geological Survey

Federal Center Mail Stop 413

Denver, CO 80225

I. J. Winograd

U.S. Geological Survey

Reston, VA 22092

F. J. Arsenault

Division of Health, Siting and Waste Management

U.S. Nuclear Regulatory Commission

Washington, DC 20555
No. of

Copies

\author{
E. Conti \\ Division of Health, Siting \\ and Waste Management \\ U.S. Nuclear Regulatory \\ Commission \\ Washington, DC 20555 \\ R. P. Denlee \\ Division of Site Safety and \\ Enviornmental Analysis \\ U.S. Nuclear Regulatory \\ Commission \\ Washington, DC 20555 \\ R. C. DeYoung \\ Division of Site Safety and \\ Environmental Analysis \\ U.S. Nuclear Regulatory \\ Commission \\ Washington, DC 20555 \\ E. O'Donnell \\ Earth Sciences Branch \\ Division of Health, Siting \\ and Waste Management \\ U.S. Nuclear Regulatory \\ Commission \\ Washington, DC 20555
F. Swanberg
Division of Health, Siting and Waste Management
U.R. Research - U.S. Nuclear Regulatory Commission
Washington, DC 20555


No. of

Copies

ONSITE

5 DOE Richland Operations Office

E. A. Bracken

M. Dayani

G. Orten

H. E. Ransom

J. D. White

9 Rockwell Hanford Operations

J.F. Albaugh

W. F. Heine

R. E. Is aacson

W. A. Jordan

J. W. Patterson

S. L. Phillips

J. F. Relyea

R. C. Routson

W. J. Waugh

UNC Nuclear Industries

P. Ortiz

Westinghouse Hanford Company

R. E. Lerch
M. Bergeron

C. R. Cole (5)

F. H. Dove

D. W. Dragnich

M. G. Foley

M. D. Freshley

G. W. Gee

M. J. Graham

P. C. Hays

E. A. Jacobson

$E$. A. Jenne

L. T. Jones

C. T. Kincaid (5)

L. T. Lakey

P. J. Mitchell

D. A. Myers

B. A. Napier

R. W. Nelson

A. E. Re isenauer

C. S. Simmons (10)

R. L. Skaggs

J. A. Stottlemyre

J. M. Thomas

G. Whelan

Publishing Coordination (2)

Technical Information (5) 